\title{
Regional ICT Innovation in the European Union: Prioritization and Performance (2008-2012)
}

\author{
Alexander Kleibrink • Björn Niehaves • Pau Palop • \\ Jens Sörvik • Basanta E. P. Thapa
}

Received: 13 January 2014 / Accepted: 5 January 2015 /

Published online: 24 January 2015

(C) The Author(s) 2015. This article is published with open access at Springerlink.com

\begin{abstract}
In the current programming period, European Union (EU) regions and member states that want to use European Regional Development Funds (ERDF) are required to develop innovation strategies for smart specialization (RIS3) based on the idea of rational strategic management. In order to explore the relationship between strategic policy design and policy performance, this article maps regional strategies for information and communication technologies (ICT) and their effects in the period 2008-2012. Furthermore, it generates suggestions for relevant case studies. We first conduct a quantitative analysis of the effects of ICT strategies and ERDF expenditure on regional ICT performance in Western European regions. ICT is a relevant priority for many regions, and it reflects EU priorities fostering ICT activities through regional development funds. Second, we propose a framework to categorize EU regions in the context of ICT policy based on the expected distribution of regional ICT performance. Our analysis covers 97 regions in 9 EU member states, out of which 29 have had a dedicated ICT strategy. In line with ideas of rational strategic management, our working hypothesis states that regions with a dedicated strategy should display better performance. However, our findings suggest that having a dedicated ICT strategy has not had a clear effect on performance in terms of Internet and broadband access, while
\end{abstract}

The views expressed are purely those of the authors and may not in any circumstances be regarded as stating an official position of the European Commission.

\footnotetext{
A. Kleibrink $(\bowtie) \cdot$ J. Sörvik

Institute for Prospective Technological Studies, European Commission, Joint Research Centre, Edificio

Expo, Calle Inca Garcilaso 3, 41092 Seville, Spain

e-mail: alexander.kleibrink@ec.europa.eu

B. Niehaves

Faculty of Information Systems, University of Siegen, Kohlbettstraße 15, 57072 Siegen, Germany

P. Palop

German Institute of Global and Area Studies, Neuer Jungfernstieg 21, 20354 Hamburg, Germany

B. E. P. Thapa

Department of Economics and Social Sciences, University of Potsdam, August-Bebel-Str. 89,

14482 Potsdam, Germany
} 
allocating dedicated ERDF and other expenditure to Internet infrastructure has had a positive effect. At first sight, this questions the effectiveness of rational strategic management. Yet, more research is needed to assess the quality of ICT strategies and their fit with broader innovation agendas. It is indeed the degree of embeddedness of ICT in the regional innovation ecosystem that is likely to condition the effect of strategies on performance. To this end, our mapping indicates interesting case studies, and we suggest additional factors to be taken into account in future analyses. New insights into strategy design and performance will also be important to inform the implementation of the new generation of innovation strategies for smart specialization.

Keywords Policy design - Smart specialization - Innovation strategies · Priority setting · Information and communication technologies (ICT)

\section{Introduction}

The European Union incentivizes the prioritization of specific policy fields by regional governments, especially with its 2014-2020 framework for the European Regional Development Fund (ERDF). To this end, the European Commission revised the relevant regulation and introduced a new legal framework for the allocation of ERDF by requiring regional and national authorities to develop dedicated regional strategies and focus their ERDF investment on existing strengths and promising economic activities like ICT development (EU Regulation 1303/2013/EU). This poses questions about the effectiveness of policy prioritization: Do regions with strategies for specific policy fields perform better in these policy fields? Does focused investment of ERDF in specific policy fields yield better performance?

To answer these questions, we examine regional policy prioritization and performance during the ERDF framework 2007-2013. Although the concern for policy prioritization was less pronounced in the previous ERDF framework, the Council of the EU already stressed greater ownership at local and regional level for the Lisbon competitiveness agenda and in its 2006 strategic guidelines for Cohesion Policy (Council Decision 2006/702/EC). We focus our inquiry on ICT policy and performance, since a number of regions had developed dedicated ICT strategies despite the absence of an explicit conditionality or legal obligation in the ERDF regulations. As ICT is one of the nine priority fields for the ERDF, the European Social Fund and the Cohesion Fund, the EU implicitly recommended this policy field for regional policy prioritization (Council Regulation 1083/2006/EC). ICT as a prioritized policy area at EU level goes to the 1990 s when the paradigm of 'information society' was increasingly streamlined into EU regional development policies (Dabinett 2001).

Using data from the ERDF framework 2007-2013, we take the opportunity to study the effects of regional political prioritization of ICT even before the new incentives for policy prioritization of the 2014-2020 framework took hold. Therefore, our findings can possibly anticipate some effects of the new framework ex ante.

The overarching goal of this article is to analyse the effect of policy prioritization of ICT by regional governments in the EU on their ICT performance as an example of policy prioritization by regional governments. For this, we first conduct a quantitative analysis of the effects of ICT strategies and ERDF expenditure on regional ICT 
performance for the period 2008 to 2012. Based on this analysis, we map EU regions according to their ICT prioritization and performance to identify interesting cases for future investigation. Finally, we discuss the implications of our findings for the current work on the new generation of smart specialization strategies and policy frameworks for digital growth.

\section{Regional Strategies, EU Innovation Policies and Rational Strategic Management}

The increasing attention given to dedicated regional strategies and targeted funding for regions in the EU is the result of the emergence of the concept of smart specialization. This concept, as developed by the European Commission and adopted by the European Parliament and the Council of the EU, builds on the accumulated knowledge from a broad range of regional innovation initiatives since the 1990s, ${ }^{1}$ general developments within regional and innovation policies, as well as more recent work carried out by Dominique Foray and the Knowledge for Growth Expert Group in the framework of the European Research Area (Foray et al. 2009). This group argued that research investments in Europe have been overly fragmented, lacked critical mass and were plagued with a pronounced 'me too' syndrome, i.e. regions investing in highly similar and fashionable areas like ICT, nano- and bio-tech.

In policy guidance documents for the next period of European Structural and Investment Funds that include ERDF, the European Commission urges regions to prioritize innovation investments in areas of strategic potential to systematically support structural change by investing in areas of strategic potential (European Commission 2012). The guidelines for developing regional innovation strategies also strongly emphasize the importance of priority setting and point out how regions should identify their unique assets, challenges, competitive advantages and potentials for excellence.

The aforementioned guidelines carry the implicit assumption that the prioritization of policy goals and the development of detailed strategies are crucial to effective policy-making. However, such a straightforward link between goal formation and policy outcomes presumes a high degree of rationality in strategic management and organizational behaviour. The classic theories of rational administrative behaviour that support these assumptions are heavily contested by concepts like bounded rationality, the influence of politics and power, and the effects of 'randomness', e.g. in the garbage can model (Olson 1971; Nelson and Winter 1982; Simon 1991; Eisenhardt and Zbaracki 1992; Pagels-Fick 2010). The orientation provided by general goals and prioritization has been shown to be helpful for policymakers to mediate between institutional inertia and dynamic changes in the environment (Mintzberg 1978). Both provide also useful steering for strategic management even if detailed plans fail (Kay 2010). In contrast, concepts like Lindblom's 'muddling through' have shown that policy implementation is more difficult given the need for coordination and the incremental and emergent nature of strategic management (Lindblom 1959). This calls into question if strategic policy prioritization can be meaningfully applied ex ante.

\footnotetext{
${ }^{1}$ Since the mid-1990s, the European Commission has issued calls for regions to participate in various projects to foster regional innovation, such as the RITTS programme (Regional Innovation and Technology Transfer Strategies), RTP (Regional Technology Plans) and RIS (Regional Innovation Strategies).
} 
Indeed, it highlights one of the main concerns of organization theorists, namely the inherent tension between policy strategies (what is ought to be done) and their actual implementation (what is done on the ground).

Following these conceptual discussions, we adopt the assumption of rational strategic management as our working hypothesis, which also reflects EU guidelines and even more pronouncedly the requirements of the 2014-2020 ERDF framework for smart specialization. That is, our analysis assumes that the political prioritization and strategic goals of a region are expressed through dedicated ICT strategies and targeted ERDF allocation, both of which are likely to result in better policy performance.

\section{Research Design}

\section{Research Design and Methods}

Based on the deliberations above, the overarching research question for our quantitative analysis reads: Does political prioritization of ICT by EU regions have an impact on their ICT performance?

Considering data availability, we break down and operationalize political prioritization as 1) the existence of a dedicated regional ICT strategy and 2) the investment of ERDF funds in ICT. Thus, we arrive at two main concrete sub-questions:

RQ1: Does the existence of a dedicated regional ICT strategy have an effect on regional ICT performance?

RQ2: Does the investment of ERDF in ICT have an effect on regional ICT performance?

Each research question is tested separately with comparisons of means for the binary independent variables (existence of an ICT strategy and the dedication of ERDF funding to ICT) in order to see whether our working hypothesis of a positive correlation between political prioritization and ICT performance holds in the different subdimensions of prioritization.

Data Collection, Variables and Descriptive Analysis

\section{Case Selection}

Starting out with the universe of all EU regions, we initially restricted our selection to EU-15 countries to establish basic comparability on the grounds of longer common EU history and roughly similar economic development in comparison to the newer EU member states. Further, we only selected countries with more than one NUTS2 2 regions to observe variance within a given country. As a last selection criterion, we used the

\footnotetext{
${ }^{2}$ NUTS are the official Nomenclature of Territorial Units for Statistics. The dataset includes information on NUTS2 level, except for Germany and UK where NUTS1 is the more appropriate level since regional development authority is assigned to this level of regional governments. EU-15 refers to the EU member states before the enlargement to Central and Eastern Europe in 2004.
} 
languages read by our team of authors as to be able to interpret regional Operational Programmes (legally binding investment plans for ERDF and other EU funding programmes) and search for regional ICT strategies in the data collection phase.

Thus, we use data from the regions of the following European countries: Italy, Spain, UK, Ireland, Belgium, Portugal, Austria, Sweden and Germany. The dataset contains information about 97 European regions, which represent $35.9 \%$ of the total NUTS2 regions of the European Union and 9 member states (or $60 \%$ ) of the EU-15 (Table 1).

\section{Independent Variables: Political Prioritization-ICT Strategies and ERDF Expenditure}

As pointed out in the research design, we use two independent variables based on ICT strategies and ERDF expenditure (Fig. 1). The binary variable 'Dedicated ICT Strategy' indicates whether a region has developed a dedicated ICT strategy during the period 2007 to 2013 . The values for this variable are determined by drawing on two different sources: the Regional Innovation Monitor database of the European Commission and a systematic Internet-based search of the top 20 results of a Google search for 'ICT policy OR Information Communication Technology OR Innovation Policy AND Name of the Region' in the respective regional/national language. ${ }^{3}$ Consequently, we establish that about one third of the regions in our sample possess a dedicated regional ICT strategy (see Table 2).

Information about investments of ERDF in particular policy fields is drawn from the Operational Programmes (OPs) presented by the regions and approved by the European Commission for the ERDF funding period 2007-2013. ${ }^{4}$ In their OPs, the regions classify the expenditure of their ERDF funds according to 74 standardized categories, out of which six (categories 10 to 15) are related to ICT. Since most of these six ICTrelated categories are quite ambiguous and therefore hard to link to concrete policy performances, we focus on the clear-cut Category 10 'Telephone infrastructure (including broadband networks)'.

Accordingly, the binary variable ERDF Investment indicates whether a region has allocated ERDF funds to category 10 or not. In our sample, roughly $40 \%$ of the regions have invested ERDF funds for telephone and broadband infrastructure (see Table 2).

\section{Dependent Variable: ICT Performance-Household Internet Access 2008/2012}

As we narrowed down ICT-related ERDF expenditure on investments in telephone and broadband infrastructure, we operationalize ICT performance as the composite variable 'Household Internet Access 2008/2012' which draws on the two Eurostat indicators that can be directly linked to these investments: One indicator that measures the percentage of households where any member of the household has the possibility to access the Internet at home at the regional level and a second indicator for the

\footnotetext{
${ }^{3}$ Regions with languages that could not be covered by the authors were coded " -1 ". The variable has been built between 20 June 2013 and 4 August 2013.

${ }^{4}$ Council Regulation (EC) No. 1083/2006 from 11 July 2006 establishes that all member states that joined the EU before 2004 had to ensure that the $60 \%$ of expenditure for the Convergence objective and the $75 \%$ of expenditure for the regional competitiveness and employment objective matched the Lisbon Agenda strategic priorities (Art. 9).
} 
Table 1 Number of regions included in the analysis per country

Source: own elaboration

\begin{tabular}{lc}
\hline Country & Number of regions included \\
\hline Austria & 9 \\
Belgium & 5 \\
Germany & 15 \\
Spain & 19 \\
Portugal & 7 \\
United Kingdom & 11 \\
Sweden & 8 \\
Ireland & 2 \\
Italy & 21 \\
Total & 97
\end{tabular}

percentage of households that are connectable to broadband Internet (based on Eurostat data for 2013).

To measure relative performance that can be compared across regions, we calculate the improvement of Household Internet and Broadband Access from 2008 to 2012, which lies within the time frame of the 2007-2013 cohesion policy framework:

Household Internet Access 2008/2012 $=\frac{(\text { Internet Access 2012 + Broadband Access 2012) }}{(\text { Internet Access 2008 + Broadband Access 2008) }}$

The resulting indicator Household Internet Access 2008/2012 has a standard deviation of 0.21 . On average, Household Internet Access has increased by $40 \%$ from 2008 to 2012 in our sample regions. The least performing region achieved an increase of $4 \%$ (Norra Mellansverige, SE), while the maximum improvement in the sample is $127 \%$ (Emilia-Romagna, IT). For further analyses, the regions have been grouped into three performance classes: 'low performance' refers to regions with less than $30 \%$ improvement in Household Internet Access, 'moderate performance' to regions with 30 to $45 \%$ improvement and 'high performance' to regions with more than $45 \%$ improvement (see Table 2).

\section{Main Hypothesis}

The main assumption in this study is that policy prioritization matters for policy performance. If this holds true, we expect to find that regions which developed a dedicated regional ICT policy and allocated ERDF budget to broadband infrastructure display high performance with regard to the improvement of Household Internet

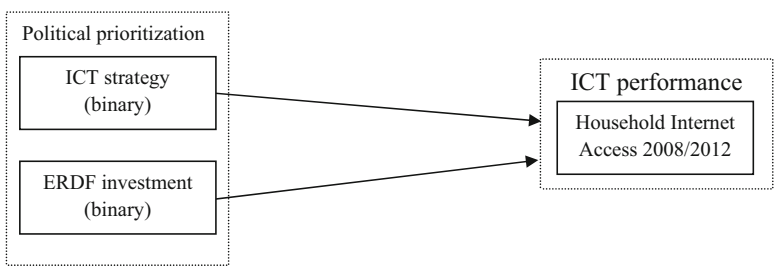

Fig. 1 Research design 
Table 2 Variables included in the analysis

\begin{tabular}{lllllll}
\hline Variable & Source & Type & Year & Values & Freq. & Percent \\
\hline ICT performance & Eurostat & Categorical & 2013 & Low & 34 & 35 \\
& & & & Moderate & 32 & 33 \\
& & & High & 31 & 32 \\
& & & & Total & 97 & 100 \\
ICT strategy & \multirow{2}{*}{ Own elaboration } & Binary & 2013 & No & 29 & 30 \\
& & & & Yes & 68 & 70 \\
& & & & Total & 97 & 100 \\
ERDF investment & ERDF OPs & Binary & 2013 & No & 40 & 41 \\
& & & & Yes & 57 & 59 \\
& & & & Total & 97 & 100 \\
\hline
\end{tabular}

Source: own elaboration

Access (H1). On the other hand, we expect moderate performance from those regions where only a dedicated ICT strategy or relevant ERDF investment can be found (H2). Finally, we expect regions that neither developed a dedicated ICT policy nor invested ERDF to telephone and broadband infrastructure to show low performance (H3); see Table 3 for a matrix of our expected results.

\section{Quantitative Analysis}

Using the data and operationalization described above, we conducted quantitative analyses for each research question.

RQ1: Does the existence of a dedicated regional ICT strategy have an effect on regional ICT performance?

Table 3 Expected distribution

\begin{tabular}{|c|c|c|c|}
\hline & & \multicolumn{2}{|l|}{ Dedicated ICT strategy } \\
\hline & & ICT strategy exists & No ICT strategy \\
\hline \multirow[t]{2}{*}{ ERDF investment } & $\begin{array}{l}\text { ERDF investment } \\
\text { in category } 10\end{array}$ & $\begin{array}{l}\text { Region has ICT strategy } \\
\text { and invests ERDF. } \\
\text { Expected results: high } \\
\text { performance }\end{array}$ & $\begin{array}{l}\text { Region has no ICT strategy } \\
\text { but invests ERDF. } \\
\text { Expected results: moderate } \\
\text { performance }\end{array}$ \\
\hline & $\begin{array}{l}\text { No ERDF investment } \\
\text { in category } 10\end{array}$ & $\begin{array}{l}\text { Region has ICT strategy } \\
\text { and does not invest ERDF } \\
\text { Expected results: moderate } \\
\text { performance }\end{array}$ & $\begin{array}{l}\text { Region has no ICT strategy } \\
\text { and does not invest ERDF } \\
\text { Expected results: low } \\
\text { performance }\end{array}$ \\
\hline
\end{tabular}

Source: own elaboration 
Whether the existence of a dedicated regional ICT strategy has a positive impact on ICT performance is tested with an analysis of variance. The $F$ value (0.006) for the relationship between the binary variable Dedicated ICT Strategy and Household Internet Access 2008/2012 is not statistically significant $(p<0.938)$. Therefore, we cannot confirm an effect of the adoption of a dedicated ICT strategy by a region on its ICT performance. In fact, a simple descriptive analysis shows that the regions without dedicated ICT strategy (39.71 \% improvement in Household Internet Access) performed on average slightly better than regions with a dedicated ICT strategy (39.35\% improvement in Household Internet Access); see also Fig. 2.

RQ2: Does the investment of ERDF funds in ICT have an effect on regional ICT performance?

Whether regions allocate ERDF to ICT (specifically telephone and broadband infrastructure) or does not have a significant impact on their ICT performance (Fig. 2). In our model, we find that regions that invest ERDF funds to telephone and broadband infrastructure on average improved their Household Internet Access by $46 \%$, while regions that did not allocate any ERDF funds to this category only increased their Internet access by an average of $34 \%$. The analysis of variance shows this correlation to be significant $(F=7.46 ; p<0.008)$.

So far, our analysis has shown that a dedicated regional ICT strategy alone did not have an impact on regional ICT performance. On the other hand, we observed that allocating ERDF expenditure to Internet infrastructure has had a positive effect on a region's improvement in Household Internet Access. As stated before, one of the objectives of this article is to map the prevalence of regional ICT strategies and identify interesting cases for further research. In this regard, our finding that simply having dedicated regional ICT strategies is statistically not significant for ICT performance certainly is a puzzle that deserves further investigation.
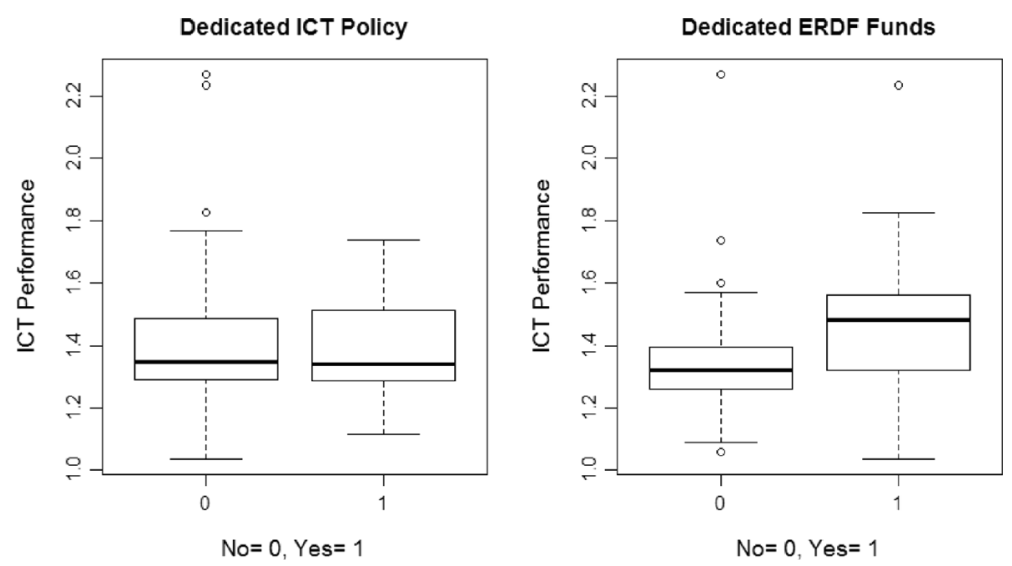

Fig. 2 Improvement in Household Internet Access from 2008 to 2012 for regions with and without ICT and ERDF investment 
In Table 4, we map the ICT performance of all 97 regions in our sample within the matrix of their expected performance based on our hypotheses. ${ }^{5}$ Only $35 \%$ of the regions behave in the expected way ( $7 \%$ with high ICT performance, $12 \%$ with moderate performance and $16 \%$ with low performance), while $65 \%$ of the regions displays performance patterns in contradiction to our hypotheses, which are based on the assumption that policy prioritization has an impact policy performance (see Fig. 3).

- Among regions with an ICT strategy and ERDF investment on Internet infrastructure, $58 \%$ (7 regions) displays high performance in accordance with our hypotheses. $25 \%$ (3) of the regions displays moderate performance and $17 \%$ (2) shows low performance.

- Among the regions without ICT strategy but with ERDF investment on Internet infrastructure, $24 \%$ (7 regions) displays moderate performance as expected, $52 \%$ (15) high performance and $24 \%$ (7) low performance.

- Among the regions with ICT strategy, but without ERDF spent in category 10, only $29 \%$ (3) perform moderately as expected. Fifteen percent (5) presents high performance, and $53 \%$ (9) presents low performance.

- Among the regions with neither ICT strategy nor ERDF spent in category $10,41 \%$ (16) presents low ICT performance as expected, $15 \%$ (6) presents high performance and $44 \%$ (17) moderate performance.

Comparing the expected performance to the actual distribution of the regions, we identify several particularly interesting cases, which are shortly highlighted below.

\section{Regions with Unexpected Outcomes}

Emilia-Romagna (ITD5) is the top performer in the sample with an increase of $126 \%$ in Household Internet Access, but neither developed a dedicated ICT strategy nor any ERDF expenditure on Internet infrastructure; displaying a behaviour entirely contrary to our expectation. Emilia-Romagna is an interesting case to identify possible additional explanatory factors for regional ICT performance.

In contrast, Mellersta Norrland (SE32) possesses a dedicated regional ICT strategy and invests ERDF funds on Internet infrastructure. However, its improvement on Household Internet Access has been rather low at only $12 \%$. Possibly, Internet access has already been highly developed in the region, so large relative improvements are difficult to achieve. Another aspect to consider is the very particular investment model for broadband in Sweden, where municipalities are the main stakeholders. Additionally, non-ERDF investments may be highly relevant here since Sweden is an economically highly developed country. Sweden has a very particular business model for broadband and fibre-to-the-home networks. Most broadband networks are owned by municipalities and are profitable. Further investigation into single case studies should also consider the financing models of Internet infrastructure.

\footnotetext{
${ }^{5}$ The results here presented are based on a cross table where the dependent variable is ICT performance and the independent variables are the existence of an ICT policy and the allocation of ERDF funds to category 10. The test for independences of all factors of the cross table is statistically significant (chisquare $16.99, p$ value $<0.02$ ).
} 


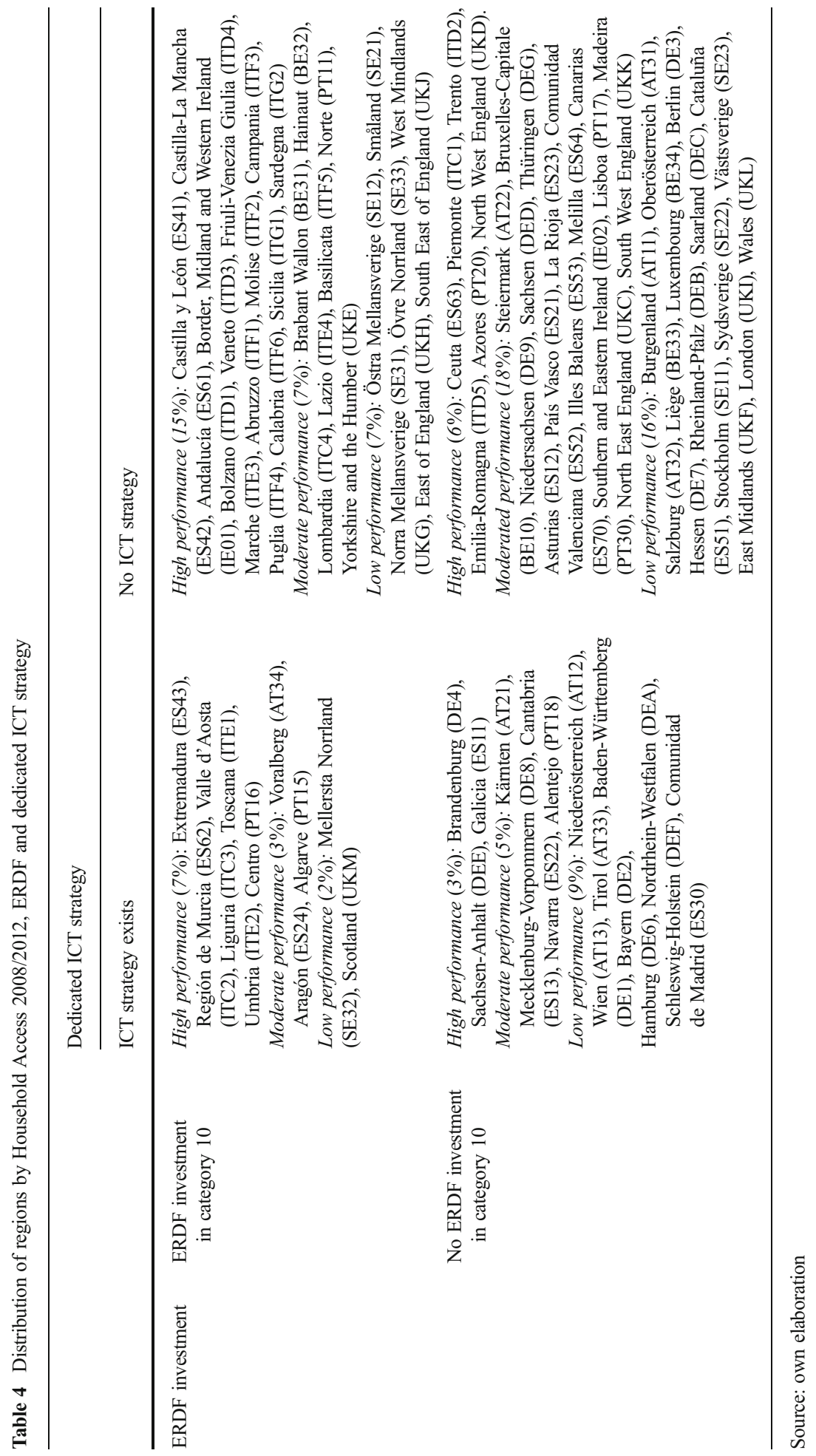


Regions with ICT Policy and ERDF Funds

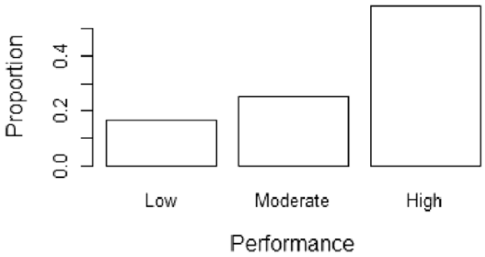

Regions with ICT Policy, but without ERDF Funds

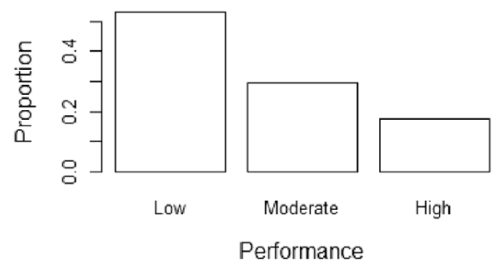

Regions without ICT Policy, but with ERDF Funds

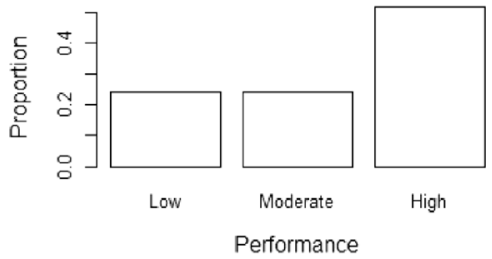

Regions without ICT Policy and without ERDF Funds

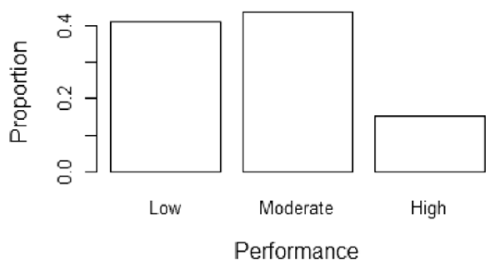

Fig. 3 Distribution of regional performance by ERDF and dedicated ICT strategy

\section{Regions with Expected Outcomes}

The Portuguese Centro region (PT16) developed a specific ICT policy and also dedicated ERDF to broadband and Internet access. As a result, Household Internet Access has improved by $54 \%$, which is above average and can therefore be classified as high performance. A similar case that lies within our expected distribution is Extremadura (ES43) that has an ICT strategy as well as dedicated ERDF and where Internet access improved by $51 \%$.

Further, we observe regions without ICT strategy and without ERDF dedicated to Internet infrastructure, which display poor improvement in Household Internet Access 2008/2012 as expected. Examples are Norra Mellansverige (SE31) in Sweden and Berlin (DE3) in Germany.

\section{Regions Without Clear Outcomes}

Stockholm (SE11) and Liège (BE33) perform rather low in Household Internet Access 2008/2012. While both count with ERDF expenditure on Internet infrastructure, neither possessed a dedicated regional ICT strategy.

\section{Conclusions}

The Europe 2020 strategy has introduced smart specialization and evidence-based innovation strategies as key processes for fostering structural change in order to drive sustainable growth. This framework strongly incentivizes EU regions to set clear policy priorities in order to access ERDF funds. To anticipate some of the consequences of the new framework, we have examined the effects of policy prioritization in EU regions on their performance with regard to Internet infrastructure during the previous funding period. 
Our findings question this general push for priority setting, since we could not find a straightforward link between policy prioritization and improved performance. In our mapping of EU regions, their ICT prioritization and performance, especially the lack of a discernible link between the development of a dedicated ICT strategy and high ICT performance is baffling. In line with the broader strategic management literature, the link between rational strategic management and policy outcomes seems to be less robust than partly put forward by management science and policy initiatives.

Yet, we must be cautious not to over-interpret these initial findings. Our measure of ICT strategies is still very simple and does not take into account their quality and their embeddedness within the broader innovation ecosystem. Only having a formalized document called 'strategy' in place does not necessarily mean it is evidence-based, well designed and its implementation is effective. All these are elements that are promoted by the idea of smart specialization for the EU funding period 2014-2020. As other policy studies remind us, any strategy document is embedded in a broader set of other existing documents and initiatives that are inter-related (Rayner and Howlett 2009). Indeed, it is important to expand the analysis of mere broadband infrastructure and access to Internet towards issues of ICT uptake and the ecosystem of advanced broadband applications. All these issues necessarily go beyond a narrow focus on broadband or ICT strategies and relate to pertinent questions of ICT-enabled innovation more broadly (OECD 2008).

Moreover, our sample covers only Western European regions. But most ERDF investments in the past and current funding period have been and will be made in Central and Eastern Europe. There, most countries have undergone a difficult transition from centrally planned communist systems to free market economies. Given this highly volatile environment and insufficient state capacities, public policies are more likely to resemble a patchwork of incongruous elements rather than rational design (Stark 1997). This is related to the degree of complexity of regional innovation systems. Less complex regional societies are more likely to have effective 'incremental strategies of problem solving', whereas more complex ones must rely on 'trial and error', which may in the best case also lead to larger performance leaps (Kitschelt 1991: 462-63). Adding East European countries and regions to future analyses will most likely require adaptations of our model and the addition of other possible explanatory factors.

Still, our mapping not only reveals puzzling results with regard to policy prioritization but also offers a promising starting point for further investigation and worthwhile case studies. Investment in Internet infrastructure from sources other than the ERDF should be taken into account. Not only the existence but also the quality of regional ICT strategies should be assessed. Aspects from the context of smart specialization, such as stakeholder involvement in policy development and implementation, mechanisms for monitoring and evaluation could also be explored. Further, national and regional characteristics and path dependencies may be of great relevance (Thelen 1999; Streeck and Thelen 2005; García et al. 2014).

With the data provided in this article, EU regions can also identify reference regions similar to them and possibly learn from good and bad practices in the strategy and implementation process. Thus, the baseline we have established will hopefully serve further studies on ICT strategy design and performance in the context of multi-level policies supporting digital growth and innovation at EU, national and regional level. 


\section{Appendix}

Coding Scheme for Cohesion Policy Expenditure Categories for ICT in the Period 2007-2013

Code 10: Telephone infrastructures (including broadband networks)

Dummy10: Dummy variable. Value 1 indicates the region assigned funding to code 10 activities. Value 0 indicates the region did not assign funding to code 10 activities.

PO10: Percentage of ERSF funding dedicated to code 10 expenditure calculated based on the total ERSF funding received by the region.

Total10: Total expenditure on code 10 activities.

Code 11: Information and communication technologies (access, security, interoperability, risk-prevention, research, innovation, e-content, etc.)

Dummy 11: Dummy variable. Value 1 indicates the region assigned funding to code 11 activities. Value 0 indicates the region did not assign funding to code 11 activities.

_ PO11: Percentage of ERSF funding dedicated to code 11 expenditure calculated based on the total ERSF funding received by the region.

Total11: Total expenditure on code 11 activities.

Code 12: Information and communication technologies

Dummy12: Dummy variable. Value 1 indicates the region assigned funding to code 12 activities. Value 0 indicates the region did not assign funding to code 12 activities.

PO12: Percentage of ERSF funding dedicated to code 12 expenditure calculated based on the total ERSF funding received by the region.

Total12: Total expenditure on code 12 activities.

Code 13: Services and applications for the citizen (e-health, e-government, e-learning, e-inclusion, etc.)

Dummy13. Dummy variable. Value 1 indicates the region assigned funding to code 13 activities. Value 0 indicates the region did not assign funding to code 13 activities.

PO13: Percentage of ERSF funding dedicated to code 13 expenditure calculated based on the total ERSF funding received by the region.

Total13: Total expenditure on code 13 activities.

Code 14: Services and applications for SMEs (e-commerce, education and training, networking, etc.)

_ Dummy14: Dummy variable. Value 1 indicates the region assigned funding to code 14 activities. Value 0 indicates the region did not assign funding to code 14 activities.

PO14: Percentage of ERSF funding dedicated to code 14 expenditure calculated based on the total ERSF funding received by the region.

Total14: Total expenditure on code 14 activities.

Code 15: Other measures for improving access to and efficient use of ICT by SMEs

Dummy15: Dummy variable. Value 1 indicates the region assigned funding to code 15 activities. Value 0 indicates the region did not assign funding to code 15 activities. 


\section{PO15: Percentage of ERSF funding dedicated to code 15 expenditure calculated based on the total ERSF funding received by the region. - Total15: Total expenditure on code 15 activities.}

Open Access This article is distributed under the terms of the Creative Commons Attribution License which permits any use, distribution, and reproduction in any medium, provided the original author(s) and the source are credited.

\section{References}

Council Regulation (1083/2006/EC). Regulation of 11 July 2006 laying down general provisions on the European Regional Development Fund, the European Social Fund and the Cohesion Fund.

Council Decision (2006/702/EC). Decision of 6 October 2006 on community strategic guidelines on cohesion.

Dabinett, G. (2001). EU mainstreaming of the information society in regional development policy. Regional Studies, 35(2), 168-173.

Eisenhardt, K. M., \& Zbaracki, M. J. (1992). Strategie decision making. Strategic Management Journal, 13, $17-37$.

EU Regulation (1303/2013/EU). Regulation of 17 December 2013 laying down common provisions on the European Regional Development Fund, the European Social Fund, the Cohesion Fund, the European Agricultural Fund for Rural Development and the European Maritime and Fisheries Fund and laying down general provisions on the European Regional Development Fund, the European Social Fund, the Cohesion Fund and the European Maritime and Fisheries Fund.

European Commission. (2012). Guide to research and innovation strategies for smart specialisation. Luxembourg: Publications Office of the European Union.

Foray, D., David, P. A., \& Hall, B. (2009). Smart specialisation. The concept. Knowledge Economists Policy Brief. Expert Group "Knowledge for Growth".

García, P. P., Thapa, B. E. P. \& Niehaves, B. (2014). Bridging the digital divide at the regional level? The effect of regional and national policies on broadband access in Europe's Regions. Electronic Government - Proceedings of the 13th IFIP WG 8.5 International Conference (EGOV 2014), 218-229

Kay, J. (2010). Obliquity: Why our goals are best achieved indirectly. London: Profile Books.

Kitschelt, H. (1991). "Industrial governance structures, innovation strategies, and the case of Japan: sectoral or cross-national comparative analysis?”. International Organization, 45(4), 453-493.

Lindblom, C. E. (1959). The science of 'Muddling Through'. Public Administration Review, 19(2), $79-88$.

Mintzberg, H. (1978). Patterns in strategy formation. Management Science, 24(9), 934-948.

Nelson, R., \& Winter, S. (1982). An evolutionary theory of economic change. Cambridge: Harvard University Press.

OECD. (2008). Broadband growth and policies in OECD countries. Paris: Organisation for Economic Cooperation and Development.

Olson, M. (1971). The logic of collective action: Public goods and the theory of groups. Cambridge: Harvard University Press.

Pagels-Fick, G. (2010). Setting priorities in public research financing. Context and synthesis of reports from China, the EU, Japan and the US. VINNOVA Analysis VA 2010:08. VINNOVA - Swedish Governmental Agency for Innovation Systems.

Rayner, J., \& Howlett, M. (2009). Conclusion: Governance arrangements and policy capacity for policy integration. Policy and Society, 28(2), 165-172.

Simon, H. A. (1991). Bounded rationality and organizational learning. Organization Science, 2(1), $125-134$.

Stark, D. (1997). Recombinant property in east european capitalism. American Journal of Sociology, 101(4), 993-1027.

Streeck, W., \& Thelen, K. (2005). "Introduction: Institutional change in advanced political economies". In W. Streeck \& K. Thelen (Eds.), Beyond continuity: Institutional change in advanced political economies (pp. 3-39). Oxford: Oxford University Press.

Thelen, K. (1999). Historical institutionalism in comparative politics. Annual Review of Political Science, 2(1), 369-404. 